\title{
Contribution of Regional Power Pools for Energy Security in Africa: Empirical Evidence from the Eastern and Southern African Regions
}

\author{
Zerubabel G. Tefera \\ Doctoral Candidate, \\ Institute of Diplomacy and International Studies, \\ University of Nairobi, Kenya \\ Maria Nzomo \\ Professor of International Relations \& Governance and Director, \\ Institute of Diplomacy and International Studies, \\ University of Nairobi, Kenya
}

DOI: https://doi.org/10.36941/mjss-2021-0054

\section{Abstract}

Despite the considerable energy problem in Africa, it is not clear how the proliferation of regional power pool (RPPs), as the most feasible solution, address the problem by fostering energy cooperation. The main research objective was to analyse and compare the role of RPPs, particularly the Eastern and Southern African power pools (EAPP and SAPP), in fostering energy cooperation and addressing energy security in their respective sub-regions. The study employed a mixed research design. The study targeted 10o leaders and senior experts from the EAPP, SAPP, regional economic communities, financial institutions, scholars, the African Union ( $A U)$, and the United Nations. Qualitative data were analysed thematically, while quantitative data was analysed via descriptive and inferential analysis. Simple linear regression models were used to test the hypotheses. From the finding, in Eastern Africa, weak power pool arrangement, EAPP, has contributed significantly to the prevailing energy insecurity $(\beta=.345, p<.05)$; on the other hand, strong regional power pool in Southern Africa, SAPP, significantly contributes to energy security $(\beta=.323, p<.05)$, thus depicting that strong RPP is a key predictor of energy security in the region. Based on the findings, the study concludes that the institutionalised attempt to energy security in Africa can address most of Africa's energy security challenges. However, Africa must embrace the role of these energy security institutions by pursuing a deliberate policy to strengthen them so that its overall integration project, as stipulated in the African Union Agenda 2063, can be materialised.

Keywords: Regional power pools, energy cooperation, EAPP, SAPP

\section{Introduction}

The strategic nature of energy resources makes energy one of the manifestations of national security. However, as much as energy is a strategic resource, the unattainability of energy independence, at least economically, makes a compelling case for energy cooperation. Considering the economic need and the configuration of energy supply chains globally, interdependence, not independence, 
describes the state of energy dynamics in the world (Bryce, 2009). Therefore, energy cooperation and interdependence among nations is the ultimate and sustainable path towards ensuring energy security.

Energy cooperation takes regional and global forms. While international markets administer oil and natural gas, regional power pool systems govern electricity-the study centres around the contribution of institutions such as power pools in promoting energy cooperation. The regional approach to energy cooperation through power pools is an arrangement where electric outputs from different utilities in each region are linked together and dispatched according to prior agreements.

States realised the inadequacy of their will and power to address global and national energy challenges unilaterally and opted for a more cooperative framework. Numerous international energy institutions have emerged to manage global energy relations and energy security concerns. States established international institutions such as the OPEC, IEA, and IEF to regulate international energy relations. Besides these global institutions, regional institutional attempts in several parts of the world address energy security challenges. African, Asian, and European counties established numerous regional institutions to promote energy cooperation and interdependence in their quest for energy security. The regional power pool arrangements in Africa are cases in point.

Regional power pooling arrangements have been in operation in several parts of the world. The first regional power pool arrangement is established in the United States when power utilities in Pennsylvania, New Jersey, Maryland (PJM) agreed to coordinate the wholesale electricity in 1927 (Economic Consulting Associates, 2010). In Europe, Nordel, a joint board composed of Denmark, Finland, Norway, and Sweden, introduced a regional power pool in 1963 to enhance cooperation in the production and transmission of power (Mundaca et al., 2013). Thus, the need to promote energy cooperation among pool members was the driving factor for the creation of PJM and Nordel regional pools.

Cognizant of the linkages between energy supply and development, the African Union Agenda for 2063, a strategic document to deliver sustainable development in the continent, recognises regional power pool as one of the strategic objectives to foster energy cooperation in Africa. Accordingly, five regional power pools (RPPs) that are EAPP in the East, SAPP in the South, WAPP in the West, and CAPP in Central Africa, have been organised to stimulate energy cooperation and interdependence in the continent. The RPPs are created to secure power supply for member states, facilitating the development of the electricity market, optimising the employment of natural energy resources, enhancing access to electricity, reducing electricity costs, and creating a conducive environment for investment. Despite the considerable energy problem in Africa, it is not clear how the proliferation of RPPs, as the most feasible solution, address the problem by fostering energy cooperation. From the literature, only a few studies discussed the contribution of RPPs, challenges, and opportunities of operationalisation in the African context. Also, there are no attempts to compare the state of energy cooperation, the challenges, and the specific enablers in the existing RPPs to draw practical lessons for policymakers. Besides, there are only a handful of academic studies that problematise RPPs in the African context. The primary study objective is to analyse and compare the role of RPPs, particularly the EAPP and SAPP, in fostering energy cooperation and addressing energy security in their respective sub-regions.

\section{Theoretical Framework}

The study focused on institutionalised energy cooperation, the role of RPPs in fostering energy cooperation, and their contribution to ensuring energy security in Africa. Thus, the theory of liberal institutionalism, which provides a peculiar perspective on the role of institutions in an increasingly interdependent world in delivering on the research objectives, has been proposed as a theoretical framework for several reasons. The liberal institutionalist theory treats institutions as both dependent and independent variables in social sciences research designs (Keohane \& Martin, 1995). Institutions can be dependent variables if the study's focus is on the context they evolve from and 
independent variables if the study wishes to bring about their effect on the behaviour of actors. Considering the argument, RPPs can be treated as both independent and dependent variables depending on research objectives. In this study, RPPs will be treated as independent variables. The study presumes that energy security in Africa depends on a successful institutionalisation of energy cooperation through RPPs.

In general, the study proposed the theory of liberal institutionalism as its theoretical framework due to its recognition of the centrality and rationality of states. Its widespread applicability further enhanced it in energy cooperation studies; and its flexibility in accommodating external variables to explain the rationale behind the magnitude of institutions' managing behaviours.

\section{Literature Review}

Many publications with empirical findings show that energy cooperation and interdependence can best describe contemporary global energy relations and presents a viable solution to energy security. Robert Bryce's book entitled "Gusher of Lies: The Dangerous Delusion of Energy Independence" argues that achieving independence in the energy spectrum is unthinkable as the global energy relation is highly interdependent. As an integral part of foreign policy decision-making, the book recommends that energy policy decision-making embrace the free market, globalisation, and interdependence than power maximisation, protectionism, and isolationism. The book made an essential contribution to mainstreaming energy cooperation in energy security problematic. Energy cooperation needs fertile ground to develop. Joseph McMillan's article in Strategic Forum entitled "Energy security in South Asia: can interdependence breed stability?" discussed these conditions in detail (McMillan, 2008). The report argued that energy intensity, soaring prices, and increased dependence on the global market make energy interdependence indispensable and inevitable. However, for interdependence to flourish, political will has to pave the way.

Jochen Prantl's work on "Cooperation in the Energy Security regime complex" examines how interdependence can flourish in security regimes (Prantl, 2011). The paper argues that if competition dominates the process of ensuring energy security, it becomes a zero-sum game leaving no or little room for cooperation. However, building an energy security regime on issues of mutual interest is indispensable in making interdependence work. As for manifestations of institutionalised energy cooperation mechanisms, energy security regimes set rules and regulations, correct market failures, and provide adequate information for energy decision making. Though the article did not mention RPPs, the description of the energy security regime as a single authority established to set rules and regulations, correct market failures, and provide adequate information for energy decision making also matches the functions of an operational regional power pool. "Multilateral Organisations and the Limits to International Energy Cooperation"(Wilson, 2015) further discusses the development and dynamics of energy cooperation involving several actors in the world. The article argues that establishing a wide range of international institutions facilitate intergovernmental energy cooperation, but with no significant success because of the challenges posed by energy price volatility, protectionism, and securitisation. This article reinforces the earlier assertion that political will and mutual trust are fundamental factors affecting the attainment of energy cooperation.

In addition, the study reviewed several publications on the RPPs. The work of Orvika Rosnes and Haakon Vennemo entitled "Powering Up: Costing Power Infrastructure Investment Needs in Southern and Eastern Africa”(Rosnes \& Vennemo, 2009) argues that different natural resource endowment, the ability to produce energy at the least cost, and the relative capability to produce more energy are the pulling factors behind regional power trade. In EAPP, the possible pattern of trade would be the elicit development of hydropower, making Ethiopia and Sudan become major power exporters. In contrast, Egypt becomes a net importer in the benefit-sharing package, allowing Egypt to save $2 \%$ and Ethiopia to gain $6 \%$ of its GDP. The paper also underscores the need for substantial investment to exploit the vast hydropower potential to meet the electrification objective across EAPP. Similar patterns also exist in the SAPP. The Democratic Republic of Congo and 
Mozambique become the significant hydropower exporters, and Angola, Botswana, Lesotho, Malawi, and Namibia would become considerable importers. The other important work of the African Development Bank, "Energy Sector Capacity Building Diagnostic \& Needs Assessment Study,"(AfDB, 2013) provides a brief history of the development of RPPs in Africa, including EAPP and SAPP, and a brief account of, including general capacity requirements and governance framework, each regional power markets.

The European Centre for Development Policy Management (ECDPM) produced a paper on "African Power Pools Regional Energy, National Power" that tried to examine the constitutive elements of RPPs and challenges of energy cooperation through institutions such as power pools in Africa. The discussion paper concluded that SAPP is relatively successful, in line with the assumption of the proposed study, but claimed that it is because of the hegemonic role played by South Africa (Medinilla et al., 2009). The paper further claimed that bilateral electric trades between member states are a challenge to regional energy markets and recommend that enormous investment and trust foster energy cooperation. The discussion paper has a methodological deficiency because it reached the conclusions mentioned above based on only secondary data sources. The study thesis will fill this gap by employing exploratory research that aims at reaching out to major players, both practitioners and academicians, in the field to obtain primary data.

The World Bank Group also produced a study entitled "Africa's Power Infrastructure Investment, Integration, Efficiency"(Foster \& Briceno-Garmendia, 2010) as part of a series designed to build knowledge on infrastructure in Africa. The technical volumes, in general, aims at providing reference material with a rich empirical foundation for economic policy decision making on the infrastructure sectors in Africa. The report mainly focused on potential power sector projects in African power pools, including EAPP and SAPP. The report underlined the centrality of cross-border trade in general and electric trade to stimulate investment and recommended that international financial institutions are better situated than private sector finance to availing adequate investment for regional electric infrastructure mainly due to risks associated with enforceability of bilateral trade agreements. Unlike ECDPM's assertion, the study did not denounce the role of bilateral electric trade agreements as a hindrance to regional electric markets. Instead, the study suggested that bilateral cross-border power transactions are building blocks to regional electric markets.

The United Nations Economic Commission for Africa produced a study entitled "Assessing Power Pooling Arrangement in Africa"(UNECA, 2004) to evaluate the efficacy of bilateral and regional electric markets in Africa. The study provided a history of cross-border electricity trade in Africa and experience of regional power pool arrangements in the western hemisphere. The study concluded that bilateral electricity exchange arrangements are the building blocks for developing potential power pools, like the World Bank study entitled "Africa's Power Infrastructure Investment, Integration, Efficiency." The timing of the study in 2004, when there was only one regional power pool, the SAPP contributed to the above assertion. The study found that SAPP has evolved from longterm bilateral electric trade and further recommended that the practice guides the development of other power pools in Africa.

The Infrastructure Consortium for Africa produced a report in 2016 entitled "Updated Regional Power Status in Africa Power Pools"(Infrastructure Consortium for Africa, 2016) to examine the possibility of attaining a functional regional power pool for Eastern Africa between $2020-2025$ and the emergence of interconnection between EAPP and SAPP. The report also identified a lack of adequate infrastructure, inadequate legal framework, financial distress, and lack of political will as the primary challenges of operationalising power pools in Africa. The lack of political will, identified as a hindrance in this updated report, was recognised as non-existent in the "Atlas of Africa Energy Resources" published by the United Nations Environment Program. The proposed study, which focuses on a comparative analysis of the success stories, challenges, and opportunities of operationalisation of RPPs in Eastern and Southern Africa, will determine whether there is an adequate political will or not.

Gaylor Montmasson-Clair and Bhavna Deonarain produced an article entitled "Regional 
Integration in Southern Africa: A Platform for Electricity Sustainability"(Montmasson-Clair \& Deonarain, 2017) that reviews the overall performance of the SAPP from an electric sustainability perspective. The article utilised concepts of electricity security, electricity equity, and environmental sustainability to assess the viability of electric supply in Southern Africa. The paper showed that the energy landscape in the SAPP region had been rapidly developing and integrating with an economywide transition to sustainability, with energy at its centre. The paper finds out that inadequate regional trading mechanism, unfounded attempt to attain energy independence; preference to a bilateral approach than a regional platform in striking long-term supply agreements; and lack of adequate transmission infrastructure are major impediments for SAPP operationalisation.

Stockholm Environment Institute published a report entitled "Powering Africa Unlocking opportunities for energy development in Southern Africa” (Stockholm Environment Institute, 2018). This paper highlighted the prevailing energy insecurity in SAPP and explored new approaches to overcome the challenges of energy insecurity in Southern Africa. The report indicated that investment in electricity infrastructure is too small to meet the increasing electricity demand for unprecedented economic growth. As a result, access to electricity remained low, and energy sources are not diversified. The report argued that regional power trade, through the SAPP, can solve the challenge if historical, political, and economic barriers can be sustainably addressed. The report also indicated that regional projects and linking such projects to industrial development objectives could help ensure benefit-sharing beyond the energy sector. However, Medhane Tadesse's work entitled "Turning Conflict to Cooperation: towards an Energy-led Integration in the Horn of Africa"(Tadesse, 2004) rejects such assertion. The book addresses issues such as conflict and cooperation in the context of regional energy integration in the Horn of Africa. The book begins by analysing the pattern of regional and civil wars in North-Eastern Africa. The proceeding part discusses how juridical statehood, a characteristic feature of the states in North-Eastern Africa, affects FP decision making and its impact on inter-state relations. Then the book explains the nature of conflict in the region further to suggest a mechanism to turn the prevailing conflict into cooperation. Finally, he argued for the prospect of economic integration and energy as a champion of regional peace in North-Eastern Africa. The liberal international relations theory highly influences the book as it underlines the centrality of states' energy needs in Africa to foster cooperation. The proposed study, which will use liberal institutionalism, will provide a more comprehensive and complementary analysis of Africa's drivers of energy cooperation.

The study identified numerous gaps in the empirical literature. The gaps are anchored on the scope, methodology, and validity of conclusions of the reviewed documents. Most of the literature reviewed is globalist and generalist in nature. Studies on energy cooperation and energy security overemphasise the traditional and mainstream sources of energy. These studies disregard hydro, wind, and solar power; overstress the role of global institutions such as the OPEC and IEA, ignoring regional institutions such as power pools. These studies also overlook Africa in their analysis and overstate the importance of the reliability of energy supplies without paying much attention to the availability of energy. Therefore, this research attempted to fill the scope and methodological gaps as well as mend the contradictions by incorporating the relevant issues into the instruments of data collection.

\section{Research Design and Materials}

The study adopted the mixed research design. This research design allowed the researcher to pursue qualitative and quantitative data and explore the multifaceted energy relations in the respective power pools characterised by their complexity due to social, political, and economic factors. The study mainly targeted leaders and senior experts from the African Union, the United Nations, EAPP, SAPP, regional economic communities, financial institutions, and scholars. The targeted participants had sufficient and recent experience in leading, coordinating, and supporting the realisation of the power pooling mechanisms in both regions. 
The researcher selected prospective research participants purposefully, which means those with relevant information were picked to answer the interview questions. Thus, the researcher chose the prospective participants from two major categories of the significant energy players in EAPP and SAPP. Purposive sampling was essential in listing and determining the study population and the key informants from the target population. The Cochran formulae were used to compute the sample size. A total of 100 respondents were sampled.

The scope of the study included the Eastern and Southern African sub-region. The researcher visited and collected data from the Eastern African Power Pool (EAPP), Southern African Power Pool (SAPP), and selected power pool member countries. Regional economic communities such as the Intergovernmental Authority on Development, the East African Community, and the Southern Africa Development Community were included in the study because they provide practical information on the role of the RPPs in the socioeconomic development of the respective regions. The sample also includes members of the individual RPPs, for example, Djibouti, Ethiopia, Kenya, South Africa, Kenya, the D.R. Congo, and Zimbabwe. Tanzania was also considered due to its unique role as a 'transit state' between EAPP and SAPP for the planned integration.

The study employed questionnaires as a method of collecting primary data because of costrelated and administration advantages. Closed and open-ended questions made the questionnaires. Likert scale was deployed by the tool whereby the research participant was provided with responses on a scale of $1-5$ where ' $1=$ strongly disagree' to ' $5=$ strongly agree.' The researcher conducted a pilot test before administering the questionnaire in the field. The study conducted a pilot test on 20 respondents who were randomly selected from a pool of energy experts from across the African continent who attended training on "Global diplomacy for the energy transition in Africa", which coincided with the study period. The results were critical in enhancing the reliability and validity of the study instrument. In addition, the study conducted key informant interviews. The researcher developed a general structure of the interview process that provided clarity and direction to the research participants without losing flexibility. The participants were encouraged to bring out their actual experiences with no interruptions without ignoring the time factor.

Collected data was both qualitative and quantitative data. The study utilised descriptive statistics to summarise the quantitative data, whereas qualitative data was organised into themes in such a way that allowed interpretation, comparisons, and generalisations. The process revolved around the research questions. In addition, the study computed composite indices for the constructs that were later used in regression analysis. They were as well used to test the hypotheses.

\section{Study Findings}

The main research objective was to analyse and compare the role of RPPs, particularly the EAPP and SAPP, in fostering energy cooperation and addressing energy security in their respective sub-regions. To achieve this, the study in the methodology articulated the interlinkage between institutions, energy cooperation and energy security. It is argued that the formation of various international institutions is mainly to facilitate intergovernmental energy cooperation, but with no significant success due to the challenges posed by energy price volatility, protectionism, and securitisation. As indicated in table 1 , the study required participants to establish the contribution made by the RPPs toward energy cooperation in Africa. These were meant to establish and conclude exhaustively on the hypothesis set in this study that regional power pool leads to energy security in Africa. Overall, the results showed an average mean score of 3.79, which was approximately 4.0, implying that the respondents agreed with most of the items regarding the contribution of RPPs to energy cooperation in Africa. 
Table 1: The interlink between RPPs and energy security

\begin{tabular}{|l|c|c|}
\hline Statement/Question & Mean & STD \\
\hline a) Regional power pools enhance/facilitate access to electricity in Africa & 3.909091 & 1.305997 \\
\hline $\begin{array}{l}\text { b) Regional power pools play a significant role in harmonising regulations, standards, } \\
\text { technical guidelines to provide affordable, reliable, and sustainable energy to the nation }\end{array}$ & 4.0000 & 1.279204 \\
\hline $\begin{array}{l}\text { c) Regional power pools play a significant role in providing uninterrupted energy to } \\
\text { customers }\end{array}$ & 3.478261 & 1.343996 \\
\hline $\begin{array}{l}\text { d) Regional power pools play a significant role in promoting renewable energy } \\
\text { investment in Africa }\end{array}$ & 3.875 & 1.329024 \\
\hline Average mean score & 3.815588 & 1.314555 \\
\hline
\end{tabular}

From the above table, statements "a," "b," and "d" showed that regional power pools enhance access to electricity, facilitate harmonisation of policy and technical standards, and promote sustainability. This is because their respective means $(M=3.9, S T D=1.3 ; M=4.0, S T D=1.3$ and $M=3.9, S T D=1.3)$ respectively were higher than the average mean score of 3.8. On the other hand, statement "c" with a mean of 3.5 and a standard deviation of 1.3 indicates that regional power pools have a lesser impact on ensuring a reliable supply of energy in Africa. It is because the corresponding mean of 3.5 was less than the average mean score. The data displayed illustrate that RPPs as established institutions correlate to energy cooperation in Africa, a prerequisite for energy security in the continent.

The study probed further to understand if energy cooperation/integration is necessary for socioeconomic development in Africa. Various strategic/political and programmatic directions were proposed. Among the main strategic moves highlighted include strengthening regional power pools, harmonised policy, and regulatory frameworks. Some respondents believed that there is a need for generating and transmitting projects, renewable technologies, and regional energy ecosystems. Specifically, one of the respondents alluded that:

"What is needed is regional energy ecosystems between generators, regulators, rural electrification agencies, sustainable energy centres, business chambers, NGOs.”

Another respondent said that:

"Building regional institutions capable of forging energy cooperation."

The researcher sought to understand whether Africa has pursued the right approach to energy cooperation and if RPPs works from the key informant interview. Respondent stated:

“...RPPs is the way to go; there is no way to explore our energy resources without regional electricity market; and so when you look at the examples of the successes of SAPP in that they have been able to set up a market which is operational; and now the volume of trade that has been traded in that market is increasing and gradually 'eating' into the market share of those trades through bilateral agreement; they are increasingly becoming competitive; so [RPPs] do work," (KII, 02)

The participant, however, acknowledged that the only problem likely to be faced is associated with the prices of electricity as the region transit from cooperative to a competitive market. The respondent argued that prices are biased because, in most cases, the countries have subsidised tariffs, so what is seen being reflected is not the actual tariff, and that may ultimately discourage investment in the sector because of very low tariffs. Further, the researcher asked another key informant to elucidate the role of regional power pools in attaining energy cooperation in Africa. In response:

"The role of power pools is to create opportunity for members to engage; also, to provide an opportunity for power utilities so that they can enter to bilateral contracts; facilitate both bilateral and regional energy cooperation; at a regional level we also go beyond and engage with other power 


$$
\text { pools..." (KII, 04). }
$$

On regional power pools in Africa, the foundation is already laid. There is a great opportunity and potential for regional markets, especially if the unexploited resources are considered on the continent. The argument is that the African regional power pools have vast opportunities. The advantages are associated with the fact that they are developed later, especially after different models pioneered in North America, Europe, and China. From the interviews conducted, the respondents concur that as markets in Africa are being developed, there are learning opportunities from all those experiences and improve on them to build a better and efficient system of electricity markets. Accordingly, the findings from empirical include the centrality of energy for economic growth and poverty reduction; power pools are vital drivers to energy integration and sustainable development, and there is an adequate political commitment to the establishment and development of RPPs. A study by UNECA (2011) examined the contribution of regional integration to economic growth and development in Africa. The report acknowledged that lack of energy is a significant hurdle to socioeconomic development in Africa. Considering the economics of regional integration, the report also recognised the crucial role RPPs could play in fostering cross-border electric trade, thereby ensuring energy security in Africa.

The study tested the hypothesis with the sole purpose of determining the contribution of RPPs in fostering energy cooperation for energy security in Africa. In particular, two hypotheses were proposed; a weak regional power pool leads to energy insecurity in Eastern Africa, and a strong regional power pool results in energy security in Southern Africa. The first sub hypothesis state that; " $\mathbf{H}_{\mathbf{a}}$ : There is a significant relationship between weak RPPs and energy insecurity in Eastern Africa." The second sub hypothesis state that " $\mathbf{H}_{\mathbf{b}}$ : There is a significant relationship between strong RPP and energy security in Southern Africa." Results are later discussed. The composite indices for each of the constructs were computed. Simple linear regression models were used to determine their significance levels. The interpretation concerning the results are based and considered on some key statistics such as " $R^{2}$ ", which is a coefficient that is a determinant on the overall course of influence, as well as "F" as a value of statistics representing overall influences related to a model and the value of $t$ and $(\beta)$ where t represents significant pertaining single factor and $\beta$ is a value-added by single variable to the dependent factor. The results are presented in Tables 2 and 3 .

Table 2: Regression Results for weak RPP and energy insecurity in Eastern Africa

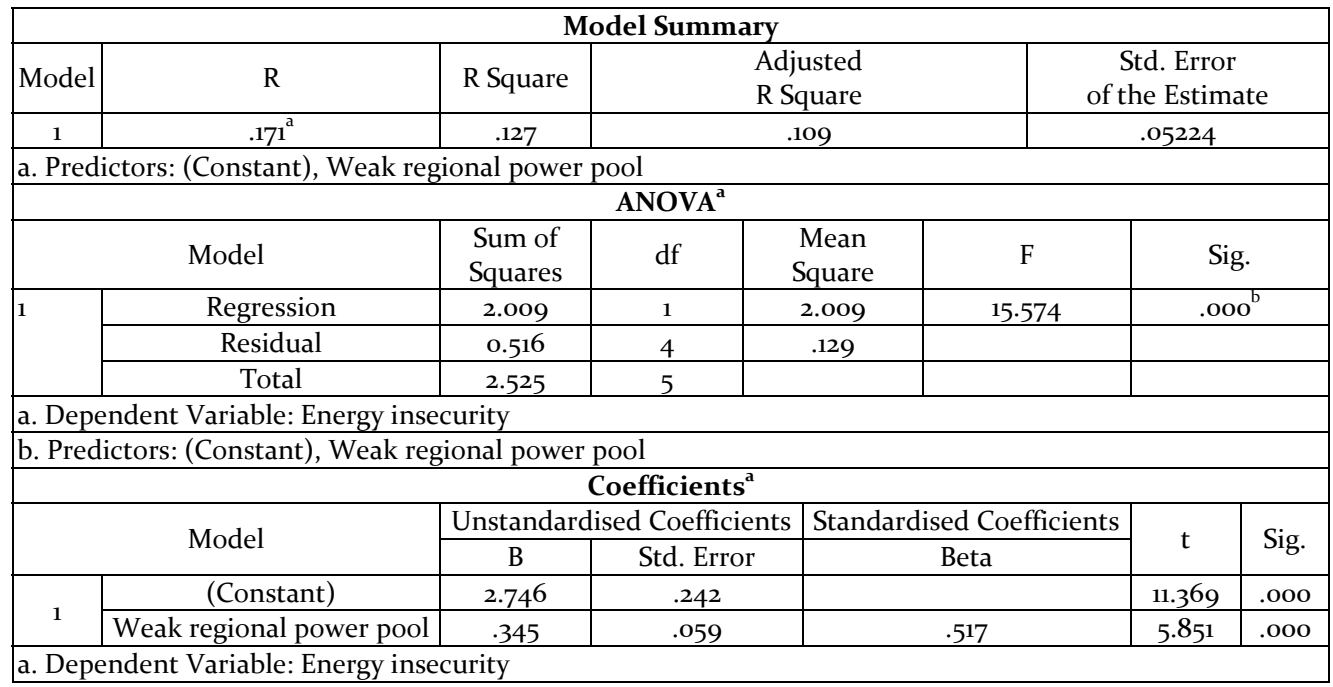


There was a relatively fair relationship between a weak regional power pool and energy insecurity $(\mathrm{R}=$ $.171) . \mathrm{R}^{2}=.127$ indicates that a weak regional power pool explains $12.7 \%$ of energy insecurity variance. Also, the overall model was significant $(\mathrm{F}=15.574, \mathrm{p}<0.05)$. The standardised beta coefficient indicates that a weak regional power pool makes a considerable contribution to energy insecurity (Beta $=.345$, $\mathrm{t}=5.851, \mathrm{p}<0.05)$, thus depicting that a weak regional power pool is key to predicting energy insecurity and hence the hypothesis that weak regional power pool significantly affects energy insecurity in Eastern Africa is accepted. Based on the outcomes of the results, the regression model explaining the relationship becomes; EINS $=2.746+.345$ WRPP, where EINS and WRPP represent energy insecurity and weak regional power pool, respectively.

Table 3: Regression Results for Strong RPP and Energy security in Southern Africa

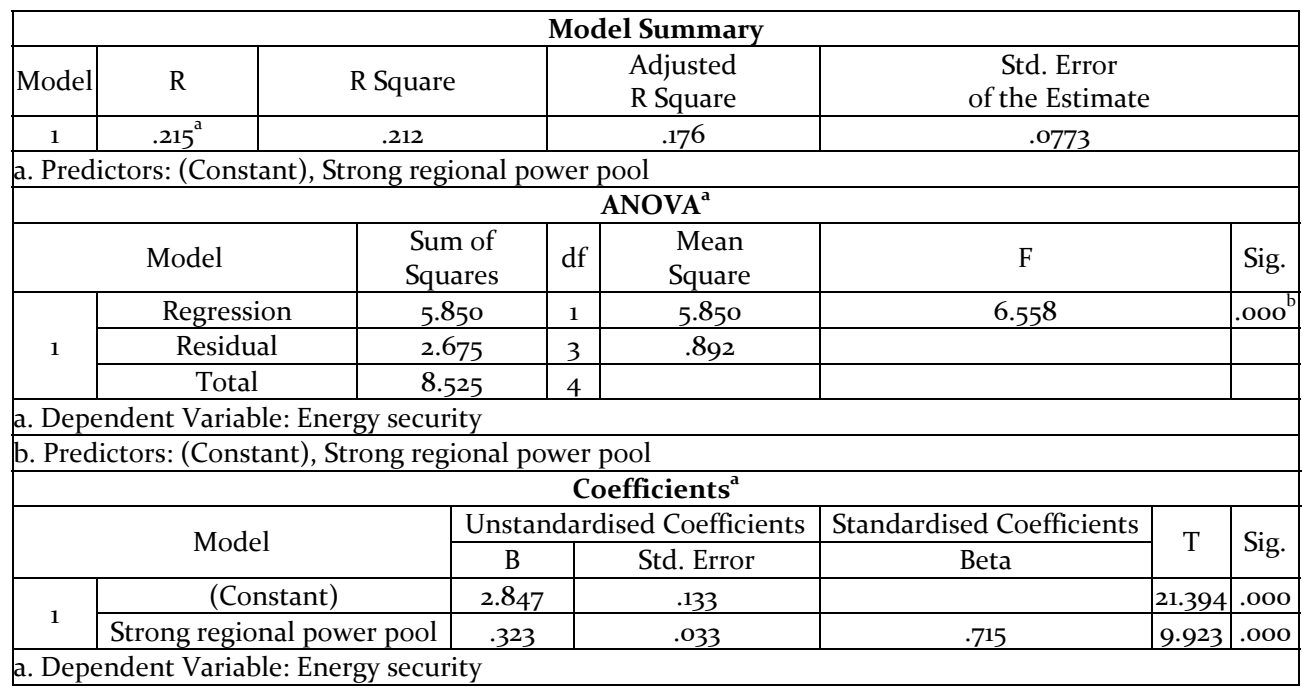

The study found a strong relationship between strong RPP and energy security $(R=.215) . R^{2}=.212$ indicates that strong RPP explain $21.2 \%$ of the variance in energy security. Overall, the model showed significance $(\mathrm{F}=6.558, \mathrm{p}<.05)$, implying it fitted the data well. The unstandardised beta coefficient indicates that strong RPP makes a significant contribution to energy security (Beta $=.323, t=9.923$, $\mathrm{p}<.05$ ), thus depicting that strong RPP is a crucial predictor of energy security in Southern Africa. Therefore, the alternative sub hypothesis was accepted. Based on the outcomes of the results, the estimated model explaining the relationship becomes; $E S=2.847+.323 S R P P$, where ES is Energy Security, and SRPP is a strong regional power pool.

\section{Discussions}

The second objective was analysed by comparing the role of RPPs, particularly the EAPP and SAPP, in fostering energy cooperation and addressing energy security in their respective sub-regions. The research question sought to determine how the Southern African and Eastern African power pools ensure energy security in their respective regions? The corresponding hypothesis was tested quantitatively and stated as; weak regional power pool leads to energy insecurity in Eastern Africa, and a strong regional power pool results in energy security in Southern Africa. Based on the analysed hypothesis, these sub hypotheses were both accepted, implying that the level or strength of RPPs significantly determines energy security or insecurity in their respective power pools. They all recorded a positive effect implying that if RPP is weaker, and so is energy insecurity, and if RPP is 
stronger, and so is the energy security status. In general, EAPP has not impacted its region as expected from a regional power pool in availing reliable, affordable, and sustainable energy to the growing demand in its expanse. On the other hand, SAPP has made encouraging progress in ensuring energy security in Southern Africa. As contained in the hypothesis, the weakness of EAPP leads to energy insecurity in Eastern Africa, and the strength of SAPP contributes to enhanced energy security in Southern Africa.

From a theoretical perspective, liberal institutionalism proposed that states establish institutions both at national and international levels to pursue areas of common interest. In this case, regional institutions such as RPPs are to address energy challenges by embracing cooperation and interdependence. The establishment of these EAPP and SAPP as regional institutions was thus significant achievements for those who subscribes to the liberal institutionalists philosophy as the world decides to tackle pressing energy security concerns by embracing interdependence and cooperation fixed on the contribution of institutions.

\section{Conclusions}

The study findings revealed that a weak regional power pool led to energy insecurity in Eastern Africa, and a strong regional power pool resulted in energy security in Southern Africa. This means, therefore, that instituting strong regional power pools would facilitate proportional distribution of energy resources across the continent. In addition, the result means that Africa can ultimately secure a long-term and stable energy market while ensuring a reliable supply of energy. In a nutshell, the African RPPs created may lead to securing power supply for member states, facilitating the development of the electricity market, optimising the employment of natural energy resources, enhancing access to electricity, reducing electricity cost, and creating a conducive environment for investment.

The centrality of energy as an input to economic development has gained much attention at national and international levels. Africa, unfortunately, remains energy-deficient despite being in abundance. The urge for sustainable development through energy cooperation in Africa is inevitable. Based on the findings, the study concludes that the institutionalised attempt to energy security in Africa can address most of Africa's energy security challenges. However, Africa must embrace the role of these energy security institutions by pursuing a deliberate policy to strengthen them so that its overall integration project, as stipulated in the African Union Agenda 2063, can be materialised.

\section{References}

AfDB. (2013). Energy Sector Capacity Building Diagnostic $\mathcal{E}$ Needs Assessment Study. https://www.afdb.org/fileadmin/uploads/afdb/Documents/Publications/Energy_Sector_Capacity_Building_ Diagnostic_and_Needs_Assessment_Study.pdf

Bryce, R. (2009). Energy Security Means Energy Interdependence. 15.

Economic Consulting Associates. (n.d.). The Potential of Regional Power Sector Integration: Literature Review (p. 66). World Bank. Retrieved 3 August 2021, from https://openknowledge.worldbank.org/bitstream/handle /10986/17501/773070v13oESMAoheoPotentialoofoRPSI.pdf?sequence=1\&isAllowed=y

Foster, V., \& Briceno-Garmendia, C. (2010). Africa's Infrastructure: A Time for Transformation. The World Bank.

Infrastructure Consortium for Africa. (2016). Updated Regional Power Status in Africa Power Pools (p. 47). https://www.icafrica.org/fileadmin/documents/Publications/Regional_Power_Pools_report_April17.pdf

Keohane, R. O., \& Martin, L. L. (1995). The Promise of Institutionalist Theory. International Security, $20(1), 39$. https://doi.org/10.2307/2539214

McMillan, J. (2008). Energy Security in South Asia: Can Interdependence Breed Stability? 232, 6.

Medinilla, A., Byiers, B., \& Karaki, K. (2009). African Power Pools: Regional energy, National Power. ECDPM.

Montmasson-Clair, G., \& Deonarain, B. (n.d.). Regional Integration in Southern Africa: A Platform for Electricity Sustainability. 65 . 
Mundaca, L., Dalhammar, C., \& Harnesk, D. (2013). The Integrated NORDIC Power Market and the Deployment of Renewable Energy Technologies: Key Lessons and Potential Implications for the Future ASEAN Integrated Power Market (pp. 25-97).

Prantl, J. (n.d.). Cooperating in the Energy Security Regime Complex. 18, 22.

Rosnes, O., \& Vennemo, H. (2009). Powering Up: Costing Power Infrastructure Spending Needs in Sub-Saharan Africa. World Bank. https://doi.org/10.1596/28073

Stockholm Environment Institute. (2018). Powering Africa Unlocking opportunities for energy development in Southern Africa (p. 22). Stockholm Environment Institute. https://cdn.sei.org/wpcontent/uploads/2018/o5/180517a-gill-johnson-powering-africa-report-18o4a.pdf

Tadesse, M. (n.d.). Turning Confelicts to Cooperation in The Horn of Africa. 170.

UNECA. (2004). Assessment of Power Pooling Arrangement in Africa. UNECA.

Wilson, J. D. (2015). Multilateral Organisations and the Limits to International Energy Cooperation. New Political Economy, 20(1), 85-106. https://doi.org/10.1080/13563467.2013.872611 